\title{
Influência da Barragem de Tucuruí no Desempenho da Pesca Artesanal, Estado do Pará
}

\author{
Antônio Cordeiro de Santana ${ }^{1}$, Elisabeth dos Santos Bentes ${ }^{2}$, \\ Alfredo Kingo Oyama Homma ${ }^{3}$, Francisco de Assis Oliveira ${ }^{4}$ e \\ Cyntia Meireles de Oliveira $^{5}$
}

Resumo: $O$ objetivo foi analisar a influência da barragem de Tucuruí no desempenho da pesca artesanal, desenvolvida a jusante. Partindo-se da hipótese de que o desequilíbrio do rio Tocantins repercutiu de forma intensa sobre a vida das comunidades humanas locais, afetando o desempenho da atividade pesqueira, procurou-se dar resposta para a seguinte questão: qual a influência da barragem de Tucuruí, estado do Pará, sobre o desempenho da pesca artesanal desenvolvida a jusante? Os dados utilizados são de origem primária e secundária. Utilizou-se o modelo de análise fatorial exploratória (AFE), para construir o Índice de Desempenho da Pesca Artesanal (IDPA). Os resultados mostram que 21\% dos pescadores têm baixo desempenho e 79\%, desempenho intermediário, fato que aponta para a difícil situação enfrentada pelos trabalhadores da pesca ao longo do tempo.

Palavras-chaves: Pesca artesanal, barragem de Tucuruí, rio Tocantins.

Abstract: The objective was to analyze the influence of the Tucurui dam in the small-scale fishery performance, developed in its downstream. Assuming that the imbalance of the Tocantins river had so intense impact over the life of local human communities, affecting their fishery activity performance, we tried to give an answer to the following question: what is the influence of the Tucurui dam, Pará state, on the performance of small-scale fishing developed in its downstream? Data used are from primary and secondary sources. We used the model of exploratory factor analysis (EFA), in order to build the performance index of small-scale fishing (IDPA). The results show that $21 \%$ of fishermen have low performance and, $79 \%$, mid-performance, a fact that points to the difficult situation faced by fishery workers over time.

Key-words: Artisanal fisheries, Tucuruí dam, Tocantins river.

Classificação JEL: C38, D62, O13.

1. Universidade Federal Rural da Amazônia (UFRA). Professor Associado IV. E-mail: acsantana@superig.com.br

2. Auditora Fiscal de Receitas Estaduais do Pará. E-mail: esbentes@gmail.com

3. Embrapa Amazônia Oriental. Pesquisador. E-mail: alfredo.homma@embrapa.br

4. Universidade Federal Rural da Amazônia (UFRA). Coordenador dos cursos de mestrado e doutoradoem Ciências Florestais. E-mail: fdeassis@gmail.com

5. Universidade Federal Rural da Amazônia (UFRA) Professora Adjunta. E-mail: cyntiamei@hotmail.com 


\section{Introdução}

Situada no rio Tocantins, estado do Pará, a Usina Hidrelétrica (UHE) de Tucuruí é a maior em potência $100 \%$ brasileira (8.370 MW), cujo funcionamento exigiu a formação de um lago artificial, que inundou uma área de $2.830 \mathrm{~km}^{2}$ (ELETRONORTE, 1989). A partir dos trabalhos de desvio do curso do rio, na década de 1970, seguido pelo fechamento da barragem, em 1984, o ambiente natural em análise passou a ter uma nova realidade, decorrente de sua fragmentação em três ecossistemas: montante, jusante e lago.

Merona (1986/1987) mostra que houve alteração no regime hidrológico da jusante da UHE, haja vista que, antes da barragem, a área tinha propriedades propícias para o desenvolvimento de uma ictiofauna diversificada e abundante: oxigenação da água acima de $7 \mathrm{mg} / \mathrm{l}$, o pH com valores entre 6,5 e 8,1, a baixa condutividade elétrica $(<50 \mathrm{~s} / \mathrm{cm})$ e a transparência entre $20 \mathrm{~cm}$ e $200 \mathrm{~cm}$.

Ao transformar um ecossistema lótico em lêntico, a barragem impactou sobre as populações aquáticas, haja vista a diminuição do tamanho e do número de peixes de água corrente (ELETRONORTE, 2007), obrigados a se adaptarem ao sistema de águas paradas. Os maiores impactos foram sobre a jusante, pois a vazante natural passou a ser controlada pela Eletronorte (COSTA, 2004). A grande extensão do ecossistema (entre os municípios de Cametá e Marabá) era um dos fatores que justificava a abundância de peixes na fase anterior ao barramento do rio; porém, a barragem estabeleceu limites à população de peixes, impedindo o acesso aos locais tradicionais de desova. Daí que, a construção e funcionamento da usina produziram externalidades negativas, que alteraram o equilíbrio do rio Tocantins, repercutindo, principalmente, sobre as comunidades da jusante da barragem, que vivem da atividade pesqueira.

A partir da década de 1980, as condições de dificuldades socioeconômicas e ambientais impostas à atividade pesqueira despertaram nos pescadores o desejo de irem à luta em busca de melhores condições de vida e de trabalho e, para superar essas dificuldades, eles vêm se organizando em associações e colônias de pesca, sob a orientação da igreja católica.

Na Amazônia brasileira, na década de 1990, segundo McGrath et al. (2004 apud McGRATH et al., 2009), as comunidades de várzea, em conjunto com diversas instituições públicas e ONGs locais, inciaram um trabalho em prol da construção de um sistema de co-manejo regional, capaz de sustentar política e institucionalmente o manejo de base ecossistêmica na várzea do Baixo Amazonas. 
Em 1998, pressionado pelas organizações e colônias de pescadores, o governo federal, por meio de medida provisória, deu poderes às comunidades para implementação dos acordos de pesca, desenvolvendo-se um movimento regional de base em apoio ao manejo comunitário dos recursos pesqueiros. A normatização desses acordos pelo Instituto Brasileiro do Meio Ambiente e dos Recursos Naturais Renováveis (Ibama), por meio da portaria n. 029/2001, representou o reconhecimento público da eficácia da iniciativa e um reforço legal para as comunidades. Os acordos de pesca constituem uma forma de democratização da gestão dos recursos pesqueiros.

Entretanto, na Amazônia, o ato só se concretizou em 2003, por meio de instrução normativa. Assim, os acordos de pesca saíram da informalidade, passaram a ser reconhecidos por pescadores de fora das comunidades e a receber o apoio do governo (ALMEIDA, 2006).

Juras et al. (2004) mostram que, com a construção da barragem de Tucuruí, a população ribeirinha de Cametá foi bastante afetada, principalmente em função da escassez de pescado. Diante dessa situação, "muitas comunidades se organizaram para regular a pesca através de acordos de pesca" (ALMEIDA, 2011, p. 1).

Conhecer a realidade do espaço em análise é de fundamental importância para a formulação de políticas públicas para a área. Neste sentido, Vasconcelos, Diegues e Sales (2007, p. 3) enfatizam que a carência de informação sobre a pesca artesanal é reflexo da "falta de atenção política" para um setor de grande importância na vida da população. Essa ausência do governo é "responsável pela escassez de investimento em pesquisa e monitoramento da pesca artesanal". Dessa maneira, a linha de pensamento desses autores evidencia a importância desta pesquisa como forma de ampliar o conhecimento sobre a atividade e contribuir para as ações governamentais voltadas para a sustentabilidade ambiental da área.

Assim, o objetivo geral deste artigo foi analisar o desempenho da pesca artesanal na jusante da barragem de Tucuruí, estado do Pará. Especificamente, procurou-se comparar as realidades da pesca artesanal realizada no rio Tocantins antes ${ }^{6}$ e depois ${ }^{7}$ da construção da UHE de Tucuruí e construir o Índice de Desempenho da Pesca Artesanal (IDPA) na jusante.

\section{Fundamentação teórica}

\subsection{Pesca artesanal}

Pasquotto e Miguel (2004) definem a pesca artesanal como atividade que se utiliza da mão de obra familiar ou de grupos próximos na relação de parentesco e vizinhança. As relações entre os membros das comunidades de pesca artesanal baseiam-se na cooperação, reciprocidade e respeito (CORDELL, 2001). Os pescadores são proprietários dos meios de produção e gestores do processo, constroem seus equipamentos e suas embarcações. Utilizam pequenas embarcações, geralmente de madeira. Seus instrumentos são: tarrafas, anzóis, redes pequenas, barcos de pequeno porte, limitados a pequenas distâncias ou com pouca capacidade de armazenamento do produto. A quantidade capturada de peixes destina-se tanto para o consumo familiar como para o mercado.

Dias Neto e Dornelles (1996, p. 4) mostram que "a pesca artesanal caracteriza-se pelo seu objetivo, que pode ser comercial e/ou de subsistência". Altmayer (1999, p. 9) reforça a ideia quanto à dimensão econômica da pesca artesanal, afirmando que o desenvolvimento dessa atividade "visa à produção de excedente, cuja venda possibilita não só a aquisição dos meios para a sobrevivência, como também a compra de instrumentos que garantam a continuidade da produção".

No contexto da pesca artesanal, além dos componentes em interação dentro do ecossis-

6. Considerou-se o período "antes" da barragem como aquele que teve início a partir das primeiras alterações no curso do rio Tocantins, na década de 1970, quando as pesquisas já passaram a registrar a redução na produção pesqueira da área, que atualmente é denominada de jusante. Esse período termina com o fechamento da barragem, em 1984.

7. O período "depois" da barragem foi considerado como aquele pós-fechamento da represa até os dias atuais. 
tema, há o componente humano, constituído pelas famílias e colônias de pescadores, cuja interação é de fundamental importância para a sustentabilidade ambiental da área. Neste contexto, incluem-se as mulheres, que "contribuem para o pluralismo econômico das famílias de pescadores, produzindo não apenas para o consumo direto do lar como também para o mercado" (MANESCHY, 2010, p. 3). Pasquotto e Miguel (2004) consideram a pesca artesanal como um sistema complexo, em que existem múltiplas interações sociais e ecossistêmicas.

Dentro de uma perspectiva socioambientalista para o uso dos recursos pesqueiros, Cerdeira (2009) cita Mamirauá, primeira Reserva de Desenvolvimento Sustentável (RDS) brasileira, criada em 1996. É uma das experiências mais significativas de manejo comunitário da pesca na região Amazônica, cujos objetivos principais são: assegurar a biodiversidade na área e garantir a manutenção das populações humanas ali residentes. Na RDS Mamirauá são desenvolvidos vários projetos de educação ambiental, entre eles o manejo sustentável dos recursos pesqueiros, cujo fortalecimento ocorreu por meio de um compromisso firmado entre os pescadores envolvidos na atividade para a pesca de rodízio. Os bons resultados levam à ampliação a cada ano da área de cobertura do projeto de manejo sustentável, haja vista que o estoque de pirarucus passou de quase 1.500 indivíduos, em 2009, para cerca de 4 mil, em 2010. São ações de importância social e ambiental, porque estão em harmonia com os princípios da conservação dos recursos pesqueiros. Além dos benefícios ao meio ambiente, há os benefícios da geração de renda para os pescadores das comunidades envolvidas.

\subsection{Impactos ambientais de barragem}

A exploração dos recursos pesqueiros além da capacidade de sustentação do ecossistema e o processo de degradação dos ecossistemas hídricos vêm despertando preocupações nas autoridades e na sociedade, por interferirem na geração de emprego e renda, devido ao enfraquecimento do setor, levando à redução no bem-estar das pessoas que dele dependem. A consequência maior de ambos é o esgotamento dos estoques de algumas espécies comerciais, fato que alcança a dimensão futura e reforça a ideia de que as ações do presente devem ser sustentáveis. O custo da superexploração desses recursos constitui uma externalidade.

A superexploração acontece em virtude de esses recursos serem considerados bens livres, não tendo um regime de propriedade definido, de modo que cada usuário pode subtrair parte do patrimônio que pertence a todos. Para Maneschy e Álvares (2010, p. 1), “as principais causas da crise da pesca se traduzem em indicadores de sobrepesca ou, mesmo, de esgotamento ou colapso de estoques de interesse comercial".

Entretanto, assim como a sobrexploração pode ser causa da redução dos estoques pesqueiros, ela pode ser efeito da diminuição desses recursos, em função de diversas causas, como é o caso das externalidades negativas decorrentes da construção de usinas hidrelétricas. Neste contexto, está inserida a UHE de Tucuruí, haja vista que as transformações provocadas pela barragem emergiram como um dos principais fatores responsáveis pelo processo de degradação da ictiofauna local. A construção da barragem promoveu a fragmentação do rio Tocantins, alterando suas condições naturais (MERONA, 1986/1987; COSTA, 2004), de modo a gerar a escassez de pescado na jusante. Como consequência, a pesca foi intensificada na área, aumentando o impacto sobre o ecossistema, cuja principal consequência foi a redução tanto da quantidade quanto da qualidade das espécies de peixes capturadas.

Na visão de Diegues (2000), a construção de hidrelétricas produz externalidades negativas sobre o ecossistema, na medida em que promove desmatamentos, contaminação dos recursos hídricos e modificações nas comunidades ecológicas e comunidades humanas, que vivem direta ou indiretamente destes recursos.

No caso da pesca na jusante da barragem de Tucuruí, é provável que o maior efeito negativo sobre as comunidades de peixes seja a inibição 
das migrações, porque, como explicam Merona et al. (2010, p. 98), "a presença da represa acentuou o isolamento da zona a jusante, impedindo os deslocamentos rio acima das espécies migradoras e limitando a recolonização da área a jusante por juvenis provenientes da área a montante".

Como reforço para a pesquisa, citam-se alguns impactos provocados pela formação do lago da hidrelétrica de Tucuruí, conforme a Comissão Mundial de Barragens (1999, p. 10): “a) interrupção da rota migratória dos grandes bagres (dourada, piraíba, pirarara e barbado) e alguns caracóides (curimatã e ubarana); b) desaparecimento inicial de curimatã; e c) diminuição do estoque pesqueiro do mapará no baixo Tocantins".

Juras, Cintra e Ludovino (2004, p. 82) apontam vários fatores para explicar a diminuição da produção pesqueira na jusante da barragem, após a formação do lago:

“(1) mudança no regime de enchente, que reflete nas condições ambientais de reprodução dos peixes; (2) empobrecimento da água decorrente da retenção de nutrientes pelo reservatório; (3) devido às regras de operação da usina, principalmente durante o período de estiagem, a água que passa para o trecho a jusante é proveniente do fundo do reservatório (camada anóxica), onde se observa um acréscimo na condutividade, sólidos totais em suspensão, ferro e, especialmente, nutrientes fosfatados e amônia; e (4) devido a alterações do ciclo hidrológico pela barragem do rio e a procedimentos operacionais da UHE de Tucuruí, ocorre elevada mortalidade de ovos, larvas e alevinos, o que compromete o recrutamento e a reposição dos estoques pesqueiros".

Os efeitos negativos da barragem da UHE de Tucuruí repercutiram com maior intensidade sobre a jusante, porque a vazante natural pas- sou a ser controlada pelo empreendimento energético, alterando esse ecossistema, como mostra Costa (2004, p. 127): "o período de águas grandes, das cheias e das vazantes, agora ficam ao sabor dos gigantescos vertedouros da hidrelétrica". $\mathrm{O}$ autor relaciona o crescimento do número de arraias e, consequentemente, o aumento do número de pescadores vitimados com o desequilíbrio ambiental provocado pela barragem.

Segundo Magalhães (2012, p. 13),

"Do ponto de vista da organização socioeconômica preexistente à construção da barragem, isso significou a desestruturação das atividades de pesca e da agricultura praticada em várzeas e ilhas, sobretudo no trecho do rio que se estende desde Baião - atravessa Mocajuba, Igarapé-Miri, Limoeiro do Ajuru até Cametá".

\section{Metodologia}

\section{1. Área de estudo}

A UHE de Tucuruí foi construída no trecho do rio Tocantins, estado do Pará, compreendido entre as cidades de Cametá e Marabá, que foi seccionado em três ecossistemas: o lago (ecossistema lêntico) e os trechos a jusante e a montante da barragem (ecossistemas lóticos). Na montante da barragem localizam-se os municípios de Itupiranga e Marabá, pertencentes à mesorregião sudeste paraense; no reservatório situam-se: Nova Ipixuna, Jacundá, Novo Repartimento, Goianésia do Pará, Breu Branco e parte do município de Tucuruí (sudeste do estado); na jusante localizam-se: Baião, Mocajuba e Cametá, pertencentes ao nordeste paraense e parte do município de Tucuruí (mesorregião sudeste), além dos municípios de Limoeiro do Ajuru e Igarapé-Miri (Figura 1). 
Figura 1. Mapa da localização da Usina Hidrelétrica (UHE) de Tucuruí, no baixo rio Tocantins, Pará: trecho entre Marabá e Cametá
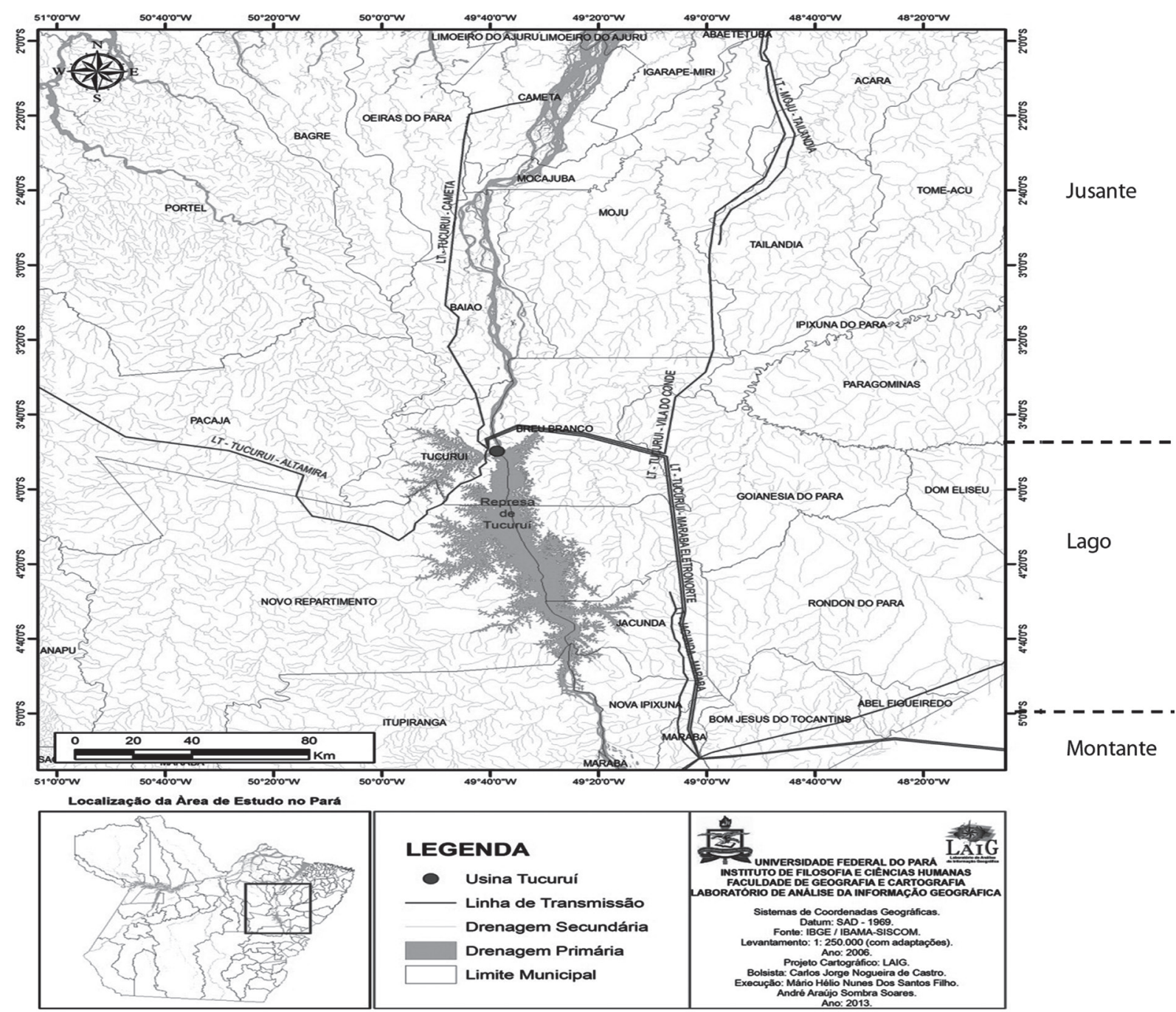

Fonte: LAIG/UFPA, 2013.

Considerou-se como área de estudo desta pesquisa a jusante da barragem de Tucuruí, por ser o ecossistema mais afetado em termos ambientais pela construção da UHE de Tucuruí e não existirem estudos sobre o desempenho da pesca artesanal local. De modo geral, a literatura existente é voltada para análises do reservatório ou trata de questões sociais, culturais e ecológicas do baixo Tocantins. Vale ressaltar que, em função da grande extensão da área, a pesquisa ficou limitada aos municípios de Baião, Mocajuba e Cametá.

\subsection{Fonte dos dados}

Os dados desta pesquisa são de natureza primária e secundária. A pesquisa de campo foi realizada no período de fevereiro de 2011 a março de 2012, por meio da aplicação de questionários aos pescadores artesanais, em 71 localidades (ilhas e vilas), próximas das sedes dos municípios pesquisados, nas quais os trabalhadores da pesca foram selecionados aleatoriamente, excluindo-se menores de idade e pescadores que não estivessem dis- 
postos a responder as questões. Em média, foram aplicados sete questionários por semana. Como complemento, foram realizadas entrevistas com pessoas ligadas à atividade, que contribuíram para ampliar o conhecimento sobre a realidade da área. A amostra contemplou 386 indivíduos retirados da população de pescadores artesanais da área de estudo ( $\mathrm{N}=33.545)$.

Os dados secundários, referentes ao período de 1970 a 2010, foram coletados nas seguintes fontes: Instituto Brasileiro do Meio Ambiente e dos Recursos Naturais Renováveis (Ibama), Centrais Elétricas do Norte do Brasil S. A. (Eletronorte) e colônias de pescadores locais. As principais variáveis analisadas foram: desembarque de pescado, renda familiar, idade, sexo, educação, escolaridade, entre outras referentes à vida pessoal, social e profissional dos pescadores, e ao seu relacionamento com o meio ambiente.

\subsection{Modelo de análise}

Para conhecer a realidade da pesca artesanal realizada na jusante da barragem de Tucuruí, estimou-se o Índice de Desempenho da Pesca Artesanal (IDPA) como medida para quantificar e classificar o desempenho dos pescadores envolvidos nessa atividade. Foi construído por meio da aplicação da Análise Fatorial Exploratória (AFE) ao conjunto de 9 variáveis selecionadas, referentes a $38 \%$ (146) dos entrevistados, que participaram da mudança histórica do rio Tocantins, ou seja, são pescadores que estão na atividade desde o período anterior às alterações no curso do rio. Somente os dados desses pescadores foram considerados no modelo. O tamanho da amostra satisfez ao estabelecido na regra geral de aplicação do modelo: "o mínimo é ter pelo menos cinco vezes mais observações do que o número de variáveis a serem analisadas e o número mais aceitável teria uma proporção de dez para um" (HAIR et al., 2009, p.108).

A técnica da análise fatorial foi utilizada para analisar a estrutura das inter-relações entre as variáveis, com vistas a identificar as dimensões latentes ou fatores comuns. Na extração dos fato- res, conforme Santana (2005) e Hair et al. (2009), utilizou-se a técnica de componentes principais, com o emprego do software SPSS 17, para eleger as componentes com raiz latente maior do que 1. Assim, cada variável contribui com um valor de pelo menos 1 do autovalor total" (SANTANA, 2005). Por isso, somente as componentes que possuem autovalores maiores que a unidade foram consideradas significantes para representar os fatores determinantes do desempenho da pesca (HAIR et al., 2009). A partir da solução composta pelos fatores extraídos foi elaborado o IDPA.

O modelo geral da análise fatorial pode ser apresentado na forma matricial, conforme Dillon e Goldstein (1984) e Santana (2005):

$$
X=\alpha F+\varepsilon
$$

Em que:

$\mathrm{X}=\left(\mathrm{X}_{1}, \mathrm{X}_{2}, \ldots, \mathrm{X}_{\mathrm{p}}\right)^{\mathrm{T}}$ é um vetor transposto de variáveis aleatórias observáveis;

$\mathrm{F}=\left(\mathrm{f}_{1}, \mathrm{f}_{2}, \ldots, \mathrm{f}_{\mathrm{q}}\right)^{\mathrm{T}}$ é um vetor transposto $\mathrm{q}<\mathrm{p}$ de variáveis não observáveis ou variáveis latentes chamadas de fatores;

$\alpha=$ matriz $(p \times q)$ de coeficientes fixos chamados de cargas fatoriais.

$\varepsilon=\left(\varepsilon_{1}, \varepsilon_{2}, \ldots, \varepsilon_{4}\right)^{\mathrm{T}}$ é um vetor transposto de termos aleatórios.

Adicionalmente, pressupõe-se que os fatores específicos são ortogonais entre si e com todos os fatores comuns. Ou seja, $\mathrm{E}(\mathrm{e})=\mathrm{E}(\mathrm{F})=0$ e $\operatorname{Cov}(\mathrm{e}$, $\mathrm{F})=0$.

Para testar a adequabilidade do modelo de análise fatorial, utilizaram-se a estatística de Kaiser-Meyer-Olkin (KMO) e o teste de Bartlett. O $\mathrm{KMO}$ é um indicador que compara a magnitude do coeficiente de correlação simples observado com a magnitude do coeficiente de correlação parcial. Levando-se em conta que os valores desse teste variam de 0 a 1, pequenos valores de KMO (abaixo de 0,50 ) indicam a não adequabilidade da análise, ou seja, valores baixos são inaceitáveis. Por sua vez, o teste de esfericidade de Bartlett serve para testar a hipótese nula de que a matriz de correlação é uma matriz identidade. Se essa hipótese for rejeitada, a análise pode ser realizada. 
Nesta pesquisa, foi utilizado o método varimax de rotação ortogonal dos fatores para a confirmação ou não da estrutura inicial quanto à determinação da matriz de cargas fatoriais com um padrão significativo de cargas das variáveis. O objetivo desse procedimento é o de redistribuir a variância dos primeiros fatores para os demais e atingir um padrão fatorial mais simples e teoricamente mais significativo, conforme Santana (2005) e Hair et al. (2009).

O procedimento da rotação (varimax) implica que o i-ésimo escore fatorial $\mathbf{F}_{\mathbf{i}}$ pode ser extraído do fator $f_{i}$ e expresso pela seguinte equação:

$$
\begin{aligned}
& F_{i}=\beta_{1} X_{i 1}+\beta_{2} X_{i 2}+\ldots+\beta_{j} X_{i j} ; i= \\
& =1,2, \ldots, q ; j=1,2, \ldots, p
\end{aligned}
$$

Em que: $\beta_{1}, \beta_{2}, \ldots, \beta_{\mathrm{p}}$ são coeficientes de regressão estimados para os $n$ escores fatoriais comuns das $\mathrm{p}$ variáveis observáveis.

O IDPA é definido como uma combinação linear dos escores fatoriais e da proporção da variância explicada pelos fatores em relação à variância comum. A fórmula matemática é dada por:

$$
\operatorname{IDPA}=\sum_{j=1}^{q}\left(\frac{\lambda_{j}}{\sum_{j} \lambda_{j}} \mathrm{FP}_{\mathrm{ij}}\right)
$$

Em que:

IDPA = Índice de Desempenho da Pesca Artesanal;

$\lambda=$ variância explicada pelos fatores;

$\Sigma \lambda=$ soma total da variância explicada pelo conjunto de fatores comuns;

$\mathrm{FP}=$ escore fatorial padronizado.

$\mathrm{O}$ escore fatorial foi padronizado (FP) para determinar os valores positivos dos escores originais e permitir a hierarquização dos pescadores. Os valores do IDPA situaram-se no intervalo de zero a um, conforme proposto por Santana et al. (2008) e foram obtidos pela fórmula:

$$
\mathrm{FP}_{\mathrm{i}}=\left(\frac{\mathrm{F}_{\mathrm{i}}-\mathrm{F}_{\min }}{\mathrm{F}_{\max }-\mathrm{F}_{\min }}\right)
$$

Em que: $\mathrm{F}_{\max }$ e $\mathrm{F}_{\min }$ são os valores máximo e mínimo observados para os escores fatoriais associados aos pescadores artesanais da área de estudo.
Para facilitar a interpretação dos resultados, utilizou-se a distribuição convencional de valores constante na literatura sobre análise fatorial, nos seguintes intervalos: valores do IDPA iguais ou superiores a 0,70 são considerados como representativos de alto desempenho; valores situados entre 0,40 e 0,69 representam desempenho médio ou intermediário e valores inferiores a 0,4 identificam os pescadores que atuam com baixo desempenho.

\subsection{Modelo econométrico da mudança na produção da pesca}

Para verificar a influência de outras variáveis não incluídas no modelo de análise fatorial sobre o desempenho da pesca artesanal, realizada na jusante da barragem de Tucuruí, utilizou-se o Método Generalizado dos Momentos (MGM), para evitar problemas de autocorrelação, heterocedasticidade e/ou multicolinearidade no modelo e não afetar a eficiência dos parâmetros estimados (GREENE, 1997; SANTANA e SANTOS, 2000; SANTANA et al., 2011). O modelo econométrico foi especificado da seguinte forma:

$$
\begin{aligned}
& Y=\beta_{0}+\beta_{1} \text { Ptraba }+\beta_{2} \text { RendaF }+\beta_{3} \mathrm{I}+ \\
& +\beta_{4} \text { IACPesca }+\beta_{5} \text { NTrabAjud }+ \\
& +\beta_{6} \text { TPesca }+\beta_{7} \text { OAtividade }+\varepsilon_{i}
\end{aligned}
$$

Em que:

$\mathrm{Y}=$ Variação porcentual nas quantidades capturadas pelos pescadores artesanais antes e depois da construção da barragem da UHE de Tucuruí; Ptraba $=$ Produtividade do trabalho, considerada como a Renda individual dividida pelas horas de trabalho do pescador;

RendaF $=$ Renda familiar mensal dos pescadores artesanais entrevistados, em R\$;

I = Idade dos pescadores artesanais entrevistados; IACPesca = Importância dos acordos de pesca, revelada por meio de pesquisa de opinião dos entrevistados e representada por uma escala de 1 a 6 pontos;

NTrabAjud $=$ Número médio de trabalhadores ajudantes por pescaria realizada;

Tpesca $=$ Tipo de pesca; 
OAtividade $=$ Outras atividades, tais como: lavoura, extrativismo vegetal, alfaiate, carpintaria e marcenaria; variável dummy, considerando 1 caso o respondente exerça outra atividade e 0 , caso contrário.

$\beta_{0}, \beta_{1}, \beta_{2}, \beta_{3}, \beta_{4}, \beta_{5}, \beta_{6}, \beta_{7}=$ coeficientes da regressão; $\varepsilon_{\mathrm{i}}=$ termo de erro.

\section{Resultados e discussão}

Nesta seção, comparam-se as realidades do rio Tocantins, antes e depois da barragem de Tucuruí, apresentam-se o perfil dos pescadores artesanais, a situação ambiental da área de estudo, os resultados gerados pela aplicação do modelo de análise fatorial, a estimativa do índice de desempenho da pesca artesanal e a análise econométrica dos resultados obtidos.

\subsection{Pesca artesanal na jusante da UHE de Tucuruí}

A fim de comparar as duas realidades do rio Tocantins, tendo como marco histórico a barragem de Tucuruí, foram utilizadas pesquisas anteriores realizadas na área de estudo. Avaliações dos três ecossistemas aquáticos (montante, reservatório e jusante), realizadas antes e depois da formação do lago, mostram que a participação da jusante da UHE diminuiu de $44 \%$ para $25 \%$ e a do reservatório aumentou de $39 \%$ para $58 \%$, fato que tem a seguinte explicação: enquanto a jusante foi prejudicada pelo represamento do rio, com alteração na qualidade da água e redução do espaço necessário para deslocamento e reprodução dos peixes, o reservatório foi beneficiado pelo aumento da área de pesca e da produção primária (CINTRA, 2009). Com a sistematização na coleta de dados, verificou-se que a média de desembarque na jusante, no período de 2000 a 2010, foi de apenas $14 \%$ (864 t) do total de 6.236 toneladas, sendo superado pelos ecossistemas a montante $(21,9 \%)$ e reservatório $(64,1 \%)$ (ELETRONORTE,
2011). Logo, a jusante continua em situação desfavorável.

Do ponto de vista local, os dados da coleta sistemática promovida na área (ELETRONORTE, 2011) mostram que, mesmo depois de decorridos, aproximadamente, 40 anos das mudanças no curso do rio Tocantins, a jusante continua em situação pior que os demais trechos do rio. Comparando-se as médias anuais, verificou-se que, no período de 2000 a 2010, os desembarques oriundos do reservatório e da montante foram, respectivamente, cerca de 5 e 2 vezes maiores que os da jusante.

A taxa de crescimento do desembarque pesqueiro nos mercados locais apresentou comportamento diverso para as quantidades capturadas nos três espaços: enquanto na montante da barragem houve queda, a uma taxa anual de $-6 \%$ a.a., no reservatório e na jusante, os desembarques apresentaram taxas de crescimento de $2 \%$ e $1 \%$ ao ano, respectivamente. Verifica-se que a recuperação da jusante ainda é muito lenta e não satisfaz as necessidades de consumo da população residente na área de estudo, pois, se considerado o consumo de peixes de água doce na região Norte igual a 10,996 quilos per capita anuais (IBGE, 2010), serão necessárias, no mínimo, 1.870 toneladas de peixes para suprir as necessidades alimentares desses habitantes, num total de, aproximadamente, 170 mil. A quantidade necessária é duas vezes superior à que vem sendo capturada na área, cuja média anual foi de 880 toneladas no período supracitado.

As análises dos dados obtidos por meio da pesquisa de campo evidenciaram as perdas, tanto na quantidade quanto na qualidade do pescado. Comparando-se as duas realidades, antes e depois do barramento do rio, verificou-se que, de acordo com a percepção dos entrevistados, a média da quantidade de peixes capturada na jusante da barragem passou de $48 \mathrm{~kg}$ para $15 \mathrm{~kg}$. Portanto, houve perda substancial de $69 \%$ da quantidade capturada ao longo do tempo, considerado desde o desvio no curso do rio para a construção da UHE de Tucuruí. 


\subsection{Perfil dos pescadores artesanais da jusante da barragem de Tucuruí entrevistados}

Conhecer as condições de vida dos pescadores é de fundamental importância para entender seu desempenho dentro da atividade pesqueira. Por isso, foram utilizados alguns dados da pesquisa de campo para traçar o perfil desses trabalhadores.

Os resultados da pesquisa nos municípios de Baião, Mocajuba e Cametá revelaram que a mão de obra familiar é predominante na atividade, haja vista que $70 \%$ dos ajudantes são parentes. O casco a remo é a embarcação usada por $98,7 \%$ dos entrevistados, predominando as embarcações de 3 a 5 metros $(78,5 \%)$. Tal fato é decorrente da própria situação financeira dos pescadores e da facilidade de aquisição da embarcação, que, geralmente, é construída pelo próprio dono e com madeira retirada de sua propriedade, além de que a maior concentração de pescadores $(61,92 \%)$ situou-se na faixa de renda familiar até R\$ 400,00. Há, ainda, uma ausência quase que total de assistência creditícia aos pescadores, haja vista que a grande maioria $(97 \%)$ nunca utilizou o crédito bancário para a compra de equipamentos, cuja razão mais forte é a falta de informações (31\%). A grande frequência de embarcações movidas a remo é uma característica da frota pesqueira paraense, conferindo ao setor um caráter predominantemente artesanal.

Em virtude da variedade de espécies encontradas no baixo Tocantins, cada pescador possui os mais diversos tipos de apetrechos, sendo que o mais utilizado $(99,22 \%)$ é a malhadeira, seguida pelo caniço e o anzol $(86,01 \%)$. A predominância desses apetrechos deve-se ao fato de que os peixes mais capturados foram a pescada branca e o mapará, conforme declaração de 56,99\% e 10,88\% dos pescadores pesquisados, respectivamente. As frequências de uso do pari $(7 \%)$ e do puçá $(4 \%)$ são mínimas, fato que favorece a conservação ambiental.

De acordo com os dados da colônia de pescadores Z-16, são 22 acordos de pesca funcionando dentro do município de Cametá, contribuindo para o aumento dos estoques e melhorar a qualidade do peixe, quantidade ainda pequena para atender as 522 comunidades distribuídas em 116 ilhas, que têm a pesca como fonte de renda e alimentação.

Para justificar a necessidade de políticas para a área, outras informações importantes foram destacadas, tais como: a participação feminina na pesca artesanal alcançou 36\% da amostra, bem próxima das participações nacional, regional e estadual, que foram iguais a $40,85 \%, 40,02 \%$ e $42,59 \%$, respectivamente (BRASIL, 2010). As idades dos entrevistados situaram-se no intervalo de 18 a 70 anos, sendo que a concentração maior $(62,18 \%)$ dos trabalhadores da pesca entrevistados ocorreu no intervalo de 18 a 39 anos, constituindo uma classe jovem de trabalhadores do rio Tocantins. Como já decorreram 28 anos após o barramento do rio Tocantins, foi possível resgatar, nas entrevistas, 146 pescadores artesanais (38\%) que tiveram ativa participação no período da construção da Hidrelétrica de Tucuruí (1976/1984) e 241 (62\%) pescadores pós-barramento, que foram complementadas com informações de dados secundários.

Apesar da baixa participação $(3,6 \%)$ do analfabetismo entre os entrevistados, observa-se que ainda há muita carência de conhecimento na área, haja vista que $86 \%$ deles não terminaram o Ensino Fundamental, que, de modo geral, se restringe às séries iniciais. O baixo nível de escolaridade é uma consequência do tempo gasto na pesca (quatro horas em média) e do esforço físico despendido, que funcionam como fatores desestimulantes para o exercício escolar, além do baixo nível de renda familiar, que os obriga ao exercício constante da atividade. O baixo nível de renda da área de estudo pode ser percebido por meio da comparação com a renda per capita do estado, cujo valor é igual a $\mathrm{R} \$$ $7.859,00$. A renda per capita da área em análise igual a $\mathrm{R} \$ 2.987,15$ representou apenas $38 \%$ da renda per capita da estadual, em 2009.

Sob o olhar dos pescadores artesanais entrevistados, a pesca é mais que uma atividade para obter renda; ela é a base de sua própria vida, pelo 
poder de sustentação que possui, em termos de segurança alimentar e nutricional, visto que apenas 9,59\% deles exercem a atividade para complementar a renda. Do total, $90 \%$ não exercem outras atividades remuneradas, dedicando-se, exclusivamente, à pesca.

Reforça-se a importância da atividade, em termos econômicos e sociais, considerando-se o ponto de vista do número de pessoas que dependem diretamente da atividade. Do total da amostra, 61,66\% (238) são casados e 38,34\% (148), solteiros. Considerando-se o número de casados e solteiros que têm filhos $(76,68 \%$ dos pescadores), a média encontrada foi igual a três filhos. Então, levando-se em conta a população de 33.545 pescadores artesanais atuando nos municípios analisados, são 128.701 pessoas que dependem diretamente da atividade, representando, aproximadamente, $76 \%$ da população residente na área de estudo (170.093 habitantes), conforme estimativa do IBGE (2010) para 2009.

\subsection{Situação ambiental da área de estudo, na visão dos entrevistados}

Assim como a realidade socioeconômica dos pescadores, a realidade ambiental da área também se reflete no desempenho da atividade, daí a necessidade de serem analisadas algumas variáveis retiradas da pesquisa de campo.

A realidade do rio Tocantins na jusante da UHE de Tucuruí foi mostrada por 386 pescadores artesanais entrevistados. Questionados sobre quais as consequências da degradação ambiental para a atividade, as mais frequentes foram: pesca predatória (30\%), desaparecimento dos peixes (29\%), contaminação da água e rio secando (16\%). Para esses pescadores, o desaparecimento de várias espécies de peixes na jusante da represa resulta da má qualidade da água, que é de cor verde, tem mau cheiro e é imprópria para consumo.

Práticas nocivas aos ecossistemas estão presentes no dia a dia dos ribeirinhos, caracterizando, muitas vezes, os conflitos pelo espaço, onde há concentração dos cardumes, especialmente no período do defeso, quando a escassez de peixes para consumo de seus familiares e/ou a ambição por ganhos financeiros levam determinados pescadores a agirem de forma incorreta. Assim, quando indagados sobre que tipo de melhoria cada pescador considera urgente para a atividade da pesca no rio Tocantins, a resposta dada por 33\% dos entrevistados foi "acabar com a pesca predatória" e "a fiscalização contra o uso da flecha, da malha fina, da fisga e do puçá".

Indagados sobre a existência de fatores prejudiciais à saúde em seu ambiente de trabalho, $40,16 \%$ dos entrevistados (155 pescadores) responderam afirmativamente, sendo que a poluição da água foi apontada como o principal fator prejudicial por $28,39 \%$ desse total, seguido de ferrada de arraia $(26,45 \%)$.

Todas essas análises são justificativas para o fato de que $96 \%$ dos pescadores artesanais que compuseram a amostra qualificaram como péssimo o atual estado do rio Tocantins para a atividade pesqueira. Ao serem questionados quanto às mudanças mais significativas na pesca desde que começaram na profissão, eles enfatizaram as condições ambientais do rio com efeitos negativos sobre a pesca e sobre a vida da população que viu a fartura de sua mesa ser prejudicada.

\subsection{Análise fatorial}

A adequação da análise fatorial foi determinada pelos testes Bartlett e KMO. O teste de esfericidade de Bartlett, no valor de 224,621, com nível de significância de $1 \%$, avaliou a significância geral da matriz de correlação e permitiu aceitar a hipótese alternativa de que as variáveis são correlacionadas, ou seja, a matriz de correlação não é diagonal. O teste $\mathrm{KMO}$, da ordem de 0,572 (maior que 0,5) é aceitável, conforme Hair et al. (2009). O determinante igual 0,204 indicou a adequação da amostra ao emprego da AFE. Estes resultados respaldam o emprego da análise fatorial para a extração de fatores e a estimação dos escores fatoriais, conforme Santana, Carvalho e Mendes (2008).

A matriz de correlação inicial foi transformada por meio de um modelo fatorial para gerar 
a matriz de cargas fatoriais. As cargas das variáveis associadas aos fatores foram interpretadas como identificadoras da estrutura latente das variáveis, que possibilitaram verificar o nível de desempenho dos pescadores artesanais da área de estudo. Aplicando o critério da raiz latente, conforme Dillon e Goldstein (1984); Gama et al. (2007), o modelo extraiu quatro fatores, cujo poder explicativo foi igual a $69,435 \%$ da variância total da nuvem de dados, o que é satisfatório pelo critério da porcentagem da variância (Tabela 1).

A Tabela 1 contém a matriz de cargas fatoriais rotacionada para os fatores extraídos do modelo estimado. Nas quatro primeiras colunas dessa matriz, foram identificadas as cargas fatoriais para cada variável associada a cada fator. As variáveis significativas que compõem cada um dos quatro fatores foram eleitas com base na significância da contribuição de cada variável. Assim as cargas significativas e de maior valor absoluto são associadas ao respectivo fator. Desse modo, os fatores $1 \mathrm{e}$ 2 têm três cargas significativas, o fator 3 tem duas cargas e o fator 4, uma carga. A quarta coluna, denominada de comunalidade, resulta da soma das cargas fatoriais ao quadrado de cada linha e detalha o grau em que cada variável é "explicada" pelas quatro componentes. A penúltima linha da tabela contém a soma da coluna de cargas fatoriais ao quadrado (autovalores), mostrando a importância relativa de cada fator na explicação da variância associada ao conjunto de variáveis analisado. As somas dos quatro fatores são 1,991, $1,786,1,387$ e 1,085, respectivamente. O número 6,249 representa a soma total de cargas fatoriais ao quadrado e indica a parcela total de variância extraída pela solução fatorial rotacionada.

A última linha da Tabela 1, denominada de porcentual do traço, mostra os fatores por ordem de importância, sendo que o primeiro fator explica a maior parcela da variância $(22,118 \%)$, e o segundo, terceiro e quarto explicam $19,849 \%$, $15,408 \%$ e $12,060 \%$, respectivamente. A soma total dos porcentuais de traço extraído para a solução fatorial serve como índice para determinar o grau de adequação da solução fatorial em relação ao que todas as variáveis representam, mostrando que, da variância total, 69,435\% são representados pela informação contida na matriz fatorial da solução em termos dos quatro fatores.

É possível observar na Tabela 1 que as variáveis que apresentaram maior peso na explicação dos quatro fatores foram: X8 - Tipo de pesca $(90,7 \%)$, X3 - Tempo de residência na comunidade $(78,5 \%)$, X6 - Renda familiar (74\%), X7 - Outras atividades $(73,1 \%), X 2$ - Idade do pescador $(72,1 \%), X 1$ - Produtividade do trabalho (64\%) e X4 - Número de filhos do pescador $(61,3 \%)$. As demais variáveis com comunalidades iguais a $58,2 \%$ e $53 \%$, mostram que uma boa parte da variância dessas variáveis não foi explicada pelos fatores.

Na composição do primeiro fator entraram as seguintes variáveis: Idade do pescador, Tempo

Tabela 1. Matriz de cargas fatoriais após a rotação ortogonal pelo método Varimax

\begin{tabular}{lccccc}
\hline \multicolumn{1}{c}{ Variáveis } & \multicolumn{3}{c}{ Fatores } & Comunalida-de \\
\cline { 2 - 5 } & $F 1$ & $F 2$ & $F 3$ & F4 & 0,721 \\
X $_{2}$ = Idade do pescador & 0,845 & $-0,087$ & $-0,009$ & 0,016 & 0,785 \\
X $_{3}$ = Tempo de residência no local & 0,875 & $-0,068$ & 0,008 & $-0,116$ & 0,613 \\
X $_{4}$ = Número de filhos do pescador & 0,583 & 0,420 & $-0,129$ & 0,281 & 0,640 \\
X $_{1}$ = Produtividade do trabalho & 0,125 & $-0,784$ & 0,094 & $-0,033$ & 0,582 \\
X $_{5}$ = Número de trabalhadores ajudantes & 0,353 & 0,671 & $-0,082$ & $-0,031$ & 0,530 \\
X $_{9}$ = Conservação do meio ambiente & $-0,151$ & 0,656 & 0,227 & $-0,160$ & 0,740 \\
X $_{6}$ = Renda familiar & 0,034 & $-0,225$ & 0,798 & $-0,226$ & 0,731 \\
X $_{7}$ = Outras atividades & $-0,078$ & 0,203 & 0,815 & 0,140 & 0,907 \\
X $_{8}$ = Tipo de pesca & $-0,017$ & $-0,108$ & $-0,034$ & 0,945 & 6,249 \\
Soma de quadrado dos autovalores & 1,991 & 1,786 & 1,387 & 1,085 & 69,435 \\
Porcentual do traço (\%) & 22,118 & 19,849 & 15,408 & 12,060 & \\
\hline
\end{tabular}

Fonte: Resultados da pesquisa. 
de residência na comunidade e Número de filhos do pescador. Todas apresentaram sinais positivos e, portanto, seus comportamentos são coerentes, considerando-se a atividade pesqueira com bom desempenho. As duas primeiras variáveis apresentaram carga fatorial elevada, significando que exercem grande influência no nível de desempenho da atividade. A explicação está no fato de que os pescadores mais velhos e que já convivem por um período mais longo na comunidade são os que têm maior experiência e maior poder de liderança dentro do grupo, em função das relações estabelecidas ao longo do tempo. Quanto ao número de filhos do pescador, a relação positiva entre as variáveis também satisfaz, uma vez que a cooperação entre os membros da família contribui para os bons resultados da atividade. Essas variáveis compõem o fator denominado de organização familiar e apontam para a importância da organização dos pescadores, com base na cooperação, solidariedade e confiança, para que a atividade alcance o nível de bom desempenho.

No fator 2, estão incluídas as variáveis: Produtividade do trabalho, Número de trabalhadores ajudantes e Conservação do meio ambiente. A primeira é negativa e as duas últimas são positivas. O comportamento da variável Produtividade do trabalho depende da relação estabelecida entre as variáveis que a compõem, ou seja, Renda individual/Horas de trabalho do pescador. Assim, um aumento na produtividade pode ocorrer nas seguintes circunstâncias: a) aumento na renda e redução nas horas trabalhadas; b) aumento na renda em proporção maior que a proporção de aumento nas horas de trabalho do pescador; c) renda constante e redução na jornada de trabalho diário. O pescador pode buscar uma produtividade maior, reduzindo suas horas de trabalho na pesca, a fim de se dedicar a uma atividade paralela que lhe proporcione algum adicional de renda. É o caso de pescadores que se ocupam no extrativismo do açaí ou na confecção de paneiros. Maior produtividade do trabalho resulta em melhor desempenho da atividade, pelo uso racional dos fatores, refletindo positivamente sobre o meio ambiente.
No caso da variável Número de trabalhadores ajudantes, o sinal positivo da carga fatorial é coerente em parte, pois, de acordo com a teoria econômica, a produção obedece à lei dos rendimentos decrescentes. Segundo esta lei, à medida que se aumenta o emprego de um dos fatores, como trabalho, por exemplo (ceteris paribus), a produção total inicialmente cresce a taxas crescentes, depois cresce a taxas decrescentes, atinge um máximo e finalmente decresce. A faixa racional de produção situa-se no segundo estágio, em que a produção total é crescente e as produtividades média e marginal são decrescentes. Portanto, qualquer acréscimo de mão de obra poderá contribuir ou não para um melhor desempenho da atividade pesqueira, dependendo do estágio de produção em que estiver inserido.

Quanto à variável Conservação do meio ambiente, pode-se dizer que há coerência na relação direta com o desempenho da atividade, uma vez que, para conservar o rio, é necessário o controle de seus estoques pesqueiros, o que pode ser feito reduzindo-se a intensidade das pescarias, resultando em pescarias mais produtivas. Essas variáveis compõem o fator representativo do desempenho produtivo, ou seja, a maneira como cada pescador exerce sua atividade frente às limitações que lhes são impostas dentro do próprio sistema.

O terceiro fator é composto pelas variáveis Renda familiar e Outras atividades que exerce, ambas com cargas fatoriais positivas e elevadas. Elas refletem a situação financeira dos pescadores e indicam que, quanto maior o poder financeiro dos pescadores, complementado por outras atividades paralelas, melhores são suas condições, em termos de apetrechos e de embarcação, contribuindo para melhorar o seu desempenho na atividade. Neste caso, é necessária a utilização de estratégias que contribuam para a melhoria econômica dos pescadores da área de estudo, como o acesso ao crédito e alternativas de geração de renda.

$\mathrm{O}$ quarto fator, denominado de pesca artesanal, é constituído pela variável Tipo de pesca, que é positiva e possui a maior carga dentre todas as variáveis em análise, refletindo a importância 
dessa atividade desenvolvida artesanalmente no contexto da atividade pesqueira como um todo. $\mathrm{O}$ fato de a pesca artesanal ser predominante na área, haja vista que é realizada por $98 \%$ dos entrevistados, pode significar que os estoques pesqueiros são explorados por meio de técnicas de mais baixo poder predatório, em comparação com a pesca industrial.

\subsection{1. Índice de Desempenho da Pesca Artesanal (IDPA)}

Para se estimar o Índice de Desempenho da Pesca Artesanal (IDPA), foram determinados os escores fatoriais associados a cada uma dessas dimensões. Os escores fatoriais originais foram padronizados a fim de determinar o IDPA e, assim, conhecer a realidade da pesca artesanal no baixo Tocantins. Esse índice é considerado como uma medida comparativa utilizada com o objetivo de classificar a posição dos pescadores dentro da atividade, levando em consideração as principais variáveis de cunho pessoal, familiar, profissional e ambiental.

Em virtude do grande número de pescadores, o resultado da aplicação do modelo foi resumido na Tabela 2. Por meio desses índices, foi possível identificar 21\% (31) dos pescadores artesanais com baixo nível de desempenho, 79\% (115) no nível intermediário e nenhum no nível alto (IDPA > 0,7). Esse resultado reflete as difíceis condições dos pescadores artesanais da área de estudo, em termos de escolaridade, renda individual e familiar, equipamentos de trabalho, infraestrutura, saúde e condições do meio ambiente.

Diante do grande número de pescadores da amostra e como forma de aprofundar a análise, foram selecionados cinco pescadores com os maio- res índices, a fim de identificar as características comuns aos mesmos. Verificou-se que seus escores fatoriais mais importantes (organização familiar e desempenho produtivo) são positivos e possuem valores altos, indicando que esses pescadores estão sabendo aproveitar os efeitos do bom relacionamento dentro da comunidade e as contribuições geradas pelo capital social. $\mathrm{O}$ desempenho desses pescadores não foi melhor em função de dificuldade financeira, refletida nas precárias condições de seus meios de trabalho, decorrentes do baixo nível de renda, já que a maioria possui renda de até $\mathrm{R} \$ 400,00$, e não têm acesso ao crédito por falta de informações sobre o processo de empréstimos.

O mesmo raciocínio foi aplicado para analisar as características comuns a cinco pescadores artesanais, classificados como atuando em nível de baixo desempenho, ou seja, com IDPA menor que 0,4 . De modo geral, seus escores fatoriais são negativos e possuem baixo valor absoluto, refletindo a precariedade das condições de trabalho na atividade.

Considerando-se o total de pescadores artesanais incluídos no modelo de análise fatorial para a determinação dos índices, verifica-se que o maior número de escores fatoriais negativos (75\%) está contido no fator F3 (situação financeira). Isto indica que o baixo nível de renda predominante na área afeta o desempenho da atividade pesqueira, em decorrência de dificuldades, principalmente para aquisição do material de pesca em condições adequadas e, até mesmo, para obter empréstimos para esse fim. A situação dos apetrechos dos entrevistados deixa a desejar, uma vez que apenas $10,6 \%$ e $1 \%$ dos pescadores possuem material em boas e ótimas condições, respectivamente. Os demais estão situados nos níveis regular $(88,1 \%)$ e ruim $(0,3 \%)$.

Tabela 2. Índices de Desempenho da Pesca Artesanal (IDPA) da jusante da UHE de Tucuruí

\begin{tabular}{lccc}
\hline \multicolumn{1}{c}{ Classificação do IDPA } & IDP & № de pescadores & Participação \% \\
\hline IDPA $<0,4 \Rightarrow$ Baixo desempenho & $0,2850-0,3994$ & 31 & 21 \\
$0,4 \leq$ IDPA $<0,7 \Rightarrow$ Desempenho intermediário & $0,4031-0,6895$ & 115 & 79 \\
IDPA $\geq 0,7 \Rightarrow$ Alto desempenho & & 0 & 0 \\
\hline
\end{tabular}

Fonte: Resultados da pesquisa. 
Tabela 3. Resultado da estimação dos parâmetros da equação da variação nas quantidades de peixes capturadas antes e depois da construção da barragem de Tucuruí

\begin{tabular}{ccccc}
\hline Variável & Coeficiente & Erro Padrão & Estatística-t & Prob. \\
\hline C & $-54,8469$ & 11,03518 & $-4,937365$ & 0,0000 \\
PTRABA & 0,163887 & 0,028588 & 5,732808 & 0,0000 \\
RENDAF & $-0,007578$ & 0,003040 & $-2,492617$ & 0,0139 \\
IDADE & $-0,495074$ & 0,179113 & $-2,764038$ & 0,0065 \\
IACPESCA & 3,006807 & 1,115004 & 2,696679 & 0,0079 \\
NTRABAJUD & $-1,881893$ & 1,172919 & $-1,604452$ & 0,1109 \\
TPESCAH & $-0,905285$ & 0,678529 & $-1,334189$ & 0,1844 \\
OATIVIDADE & 5,342224 & 3,483857 & 1,533422 & 0,1275 \\
\hline R $^{2}$ & 0,344396 & Média da variável dependente & $-62,60547$ \\
R $^{2}$ ajustado & 0,310899 & S.D. da var. dependente & 16,26962 \\
S.E. da regressão & 13,0576 & Soma dos quadrados dos resíduos & 24989,55 \\
Durbin-Watson & 1,350515 & \multicolumn{2}{c}{ Estatística-J } & Prob. (Estatistica) \\
Instrument rank & 14 & \multicolumn{2}{c}{0,050997} \\
\hline
\end{tabular}

Fonte: Resultados da pesquisa de campo.

\subsection{Análise econométrica}

A fim de avaliar o grau de influência das variáveis independentes na variação porcentual da quantidade capturada de peixes na jusante da barragem, antes e depois da mudança no curso do rio Tocantins, foi estimada a regressão, cujos resultados estão na Tabela 3.

$\mathrm{O}$ coeficiente de determinação $\mathrm{R}^{2}$ ajustado indica que $31,1 \%$ das variações nas quantidades capturadas são explicadas pelas variáveis incluídas na regressão. Com base na estatística $t$ dos parâmetros e na probabilidade (valor $p)^{8}$, verifica-se a significância a $1 \%$ de probabilidade de erro do intercepto e das quatro primeiras variáveis (Produtividade do trabalho, Renda familiar, Idade do pescador e Importância dos acordos de pesca). As variáveis Número de ajudantes e Outras atividades são significativas a $15 \%$ e o Tempo de pesca (em horas), a $20 \%$. Os $p$ valores iguais a $11,09 \%$, $18,44 \%$ e 12,75\% são perfeitamente aceitáveis "já que, com amostras extremamente grandes, quase toda hipótese nula será rejeitada" (GUJARATI, 2000, p. 123), situação considerada adequada para esta pesquisa.

8. $\quad p$ - nível de significância observado ou exato - é o mais baixo nível de significância com o qual a hipótese nula pode ser rejeitada.
O sinal negativo do intercepto da equação estimada está coerente, uma vez que a construção da barragem de Tucuruí produziu externalidades negativas que contribuíram para a degradação ambiental do rio Tocantins, refletida na pesca artesanal pela redução dos estoques pesqueiros, principalmente.

Considerando-se que a variável Produtividade do trabalho é determinada pela Renda individual/ Horas de trabalho do pescador, o sinal positivo do coeficiente está de acordo com o esperado, uma vez que o pescador pode aumentar a produtividade, diminuindo as horas despendidas na pesca e alocando-as em outras atividades remuneradas, de forma que sua renda tende a aumentar. É possível, também, com o mesmo tempo despendido na pesca, aumentar a produtividade em função da tecnologia, conhecimento e infraestrutura. $\mathrm{O}$ resultado mostra que aumento na produtividade do trabalho impacta positivamente na variação da produção. O sinal negativo do coeficiente da variável Renda familiar (RENDAF) é coerente, levando-se em conta que, se a renda do pescador aumenta, ele deixa a atividade e a variação entre as quantidades capturadas cai.

No caso da variável idade, pode-se esperar tanto uma diminuição nas capturas, em virtude das condições de saúde e desgastes físicos dos pescadores com o passar dos anos quanto um 
aumento nas capturas pelo nível de experiência adquirido ao longo do tempo. Portanto, o sinal do parâmetro estimado está conforme o esperado.

O sinal positivo do parâmetro da variável Importância dos acordos de pesca (IACPESCA) é perfeitamente aceitável, uma vez que esses acordos levam ao controle das pescarias de forma que a variação entre as quantidades capturadas aumenta. A variável Número de trabalhadores ajudantes (NTRABAJUD) apresentou coeficiente negativo, situação que pode ser aceita, desde que seja considerado o primeiro ou o segundo estágios de produção, nos quais o aumento do fator trabalho (ceteris paribus) levará a aumento na produção e, consequentemente, redução na variação entre as duas quantidades.

O coeficiente negativo da variável Tempo de pesca em horas (TPESCAH) é coerente, porque o aumento de horas trabalhadas pode levar a aumento na produção, fazendo com que diminua a variação nas quantidades.

No caso da variável Outras atividades (OATIVIDADE), o sinal do coeficiente é positivo e dentro do esperado, pois, quando o pescador passa a ter outras atividades, deixa de lado a pesca, de forma que a quantidade capturada diminui e a variação entre as quantidades aumenta.

\section{Conclusões}

As externalidades negativas produzidas pela barragem da UHE de Tucuruí na jusante e seus efeitos sobre o desempenho da atividade pesqueira desenvolvida artesanalmente na área evidenciaram as perdas, tanto na quantidade quanto na qualidade do pescado. De acordo com a percepção dos pescadores artesanais entrevistados, a quantidade pescada nos anos recentes representa apenas $31 \%$ daquela obtida no passado, ou seja, houve uma perda substancial de $69 \%$ ao longo de, aproximadamente, quatro décadas, contribuindo para a deterioração da qualidade de vida dos ribeirinhos da área.

Os quatro fatores extraídos pelo modelo são representativos das dimensões que deter- minam o desempenho da atividade pesqueira desenvolvida artesanalmente na área de estudo: Organização familiar, Desempenho produtivo, Situação financeira e Pesca artesanal. Os porcentuais de explicação da variância total de cada um dos fatores foram de $22,12 \%, 19,85 \%, 15,41 \%$ e $12,06 \%$, respectivamente.

Essas dimensões permitiram estimar os escores fatoriais utilizados na construção do Índice de Desempenho da Pesca Artesanal (IDPA), que possibilitou classificar os pescadores, conforme seus níveis de desempenho, em intermediário e baixo. 79\% dos pescadores situaram-se no nível intermediário, em decorrência principalmente dos efeitos positivos dos dois primeiros fatores. O desempenho desse conjunto de pescadores não foi melhor por força da precariedade econômica e financeira registrada na área e representada pelos escores fatoriais negativos e de baixo valor absoluto. Mais de $20 \%(21 \%)$ dos trabalhadores da pesca apresentaram baixo desempenho, revelando a debilidade da atividade, refletida no grande número de escores fatoriais negativos. Nenhum pescador teve bom desempenho, fato que leva a concluir que isto acontece provavelmente em função de baixa produtividade da atividade, decorrente das condições não satisfatórias dos apetrechos e das próprias condições de cada trabalhador.

Considerando-se a média e a mediana, 51\% dos pescadores pesquisados foram enquadrados acima do IDPA médio e mediano. O conjunto de pescadores com IDPA abaixo dessas duas medidas apresentou debilidade em pelo menos três das quatro dimensões fatoriais. Estes resultados podem servir para orientar as tomadas de decisões quanto às medidas a serem tomadas para a evolução do desempenho dos trabalhadores da pesca.

O processo de construção do IDPA permitiu identificar o nível de desempenho dos pescadores da área de estudo, assim como a dimensão fatorial em que a atividade é vulnerável, mostrando-se adequado para orientar a formulação de estratégias políticas para a área. Assim, tem-se a renda como uma das variáveis prioritárias nas políticas públicas para a área, não somente pelas condições de pobreza desses pescadores, 
haja vista que $61,92 \%$ deles possuem renda familiar mensal de até $\mathrm{R} \$ 400,00$, como também pela importância que ela assume para a melhoria de vida desses trabalhadores, que têm um papel relevante no desenvolvimento socioeconômico e ambiental do baixo Tocantins.

Além disso, a realidade da área, apresentada nesta pesquisa, evidenciou outras carências que precisam ser supridas por meio de ações eficientes, como é o caso do baixo nível de conhecimento, percebido nas respostas de $86 \%$ dos entrevistados que alcançaram apenas as séries iniciais do Ensino Fundamental. Há, ainda, o baixo grau de organização dos pescadores, a precariedade sanitária e a carência de cuidados com o meio ambiente, haja vista o número reduzido de acordos de pesca diante da extensão da área, o uso de água sem tratamento pela maioria dos residentes e a poluição da água, tanto pelo lixo lançado no rio quanto produzida pela UHE. Diante da realidade da área de estudo apresentada ao longo do texto, considera-se que as ações com grandes possibilidades de melhorias para a atividade pesqueira desenvolvida artesanalmente situam-se, principalmente, no âmbito da educação ambiental e das organizações comunitárias.

\section{Referências bibliográficas}

ALMEIDA, O. T. Manejo na pesca amazônica. In: ALMEIDA. O. T. (Org.). Manejo de Pesca na Amazônia brasileira. São Paulo: Petrópolis, 2006.

. et al. Uma análise dos acordos de pesca em Cametá. Reunião do SBPC, 63. UFG. Anais... Goiânia - GO. Jul. 2011. Disponível em: <www.sbpcnet.org.br/ livro/63ra/resumos/resumos/2211.htm > Acesso em: 18 set. 2013.

ALTMAYER, F. de L. Pescadores artesanais do estuário da Lagoa dos Patos - RS: uma análise de sua percepção do meio natural como subsídio para um projeto de educação ambiental. 1999. Dissertação (Mestrado em Educação Ambiental). Rio Grande. 1999.

BRASIL. Ministério da Pesca e Aquicultura (MPA). Boletim da Pesca e Aquicultura 2010. Brasília, fevereiro de 2012. Disponível: <http://www.mpa.gov.br/
images/Docs/Informacoes_e_Estatisticas/Boletim $\% 20$ Estatístico\% 20MPA\%202010.pdf>. Acesso em: 20 jun. 2012.

CERDEIRA, R. G. P. Acordo de pesca como instrumento de gestão participativa. Dissertação (Mestrado em Direito ambiental) - Universidade do Estado do Amazonas. Manaus, 2009.

CINTRA, I. H. A. A pesca no reservatório da Usina Hidrelétrica de Tucuruí, Estado do Pará, Brasil, 2009. Tese (Doutorado em Engenharia de Pesca) - Universidade Federal do Ceará. Fortaleza, 2009.

COMISSÃO MUNDIAL DE BARRAGENS (CMB). Estudo de Caso Brasileiro, UHE de Tucuruí. Relatório de escopo - Ago. 1999.

CORDELL, J. Marginalidade social e apropriação territorial marítima na Bahia. In: DIEGUES, A. C. S.; MOREIRA, A. C. (Org.). Espaços e recursos naturais de uso comum. São Paulo: NUPAUB, p. 139-158, 2001.

COSTA, G. S. Desenvolvimento rural sustentável com base no paradigma da agroecologia: estudo sobre a região das ilhas em Cametá, Pará-Brasil. 2004. Dissertação (Mestrado em Planejamento do Desenvolvimento - PLADES) - Núcleo de Altos Estudos Amazônicos - NAEA, Universidade Federal do Pará - UFPA. Belém. 2004.

DIAS NETO, J.; DORNELLES, L. D. C. Diagnóstico da pesca marítima no Brasil. Brasília: IBAMA, 1996. 163p.

DIEGUES, A. C. S. Etnoconservação da Natureza: enfoques alternativos. In: DIEGUES, A. C. (Org.). Etnoconservação: novos rumos para a proteção da natureza nos trópicos. São Paulo: Hucitec, 2. ed. 2000. p. 1-46.

DILLON, W. R.; GOLDSTEIN, M. Multivariate analysis: method and applications. New York: John Wiley \& Sons, 1984.

ELETRONORTE. 1989. Plano de utilização do reservatório: a pesca nas áreas de influência local e de jusante caracterização preliminar (TUC 10-26443-RE). Centrais Elétricas do Norte do Brasil, S/A, Brasília. 124p. (Relatório).

- Relatório Socioambiental. Centrais Elétricas do NortedoBrasil,S/A,Brasília,2007.Disponívelem: < http:// www.eln.gov.br/opencms/export/sites/eletronorte/ publicacoes/publicacoes/RelatorioSocioAmbiental2007. pdf>. Acesso em: 20 mai. 2011.

Desembarque de produção pesqueira na área da influência da usina hidrelétrica. Superintendência de Produção Hidráulica - CPH Tucuruí. Divisão de Ações Ambientais de Geração - CPHM. Tucuruí: Set. 2011. 
GAMA, Z. J. C. et al. Índice de desempenho competitivo das empresas de moveis da região metropolitana de Belém. Revista de Economia e Agronegócio, v. 5, n. 1, 2007.

GREENE, W. H. Econometric Analysis. 3. ed. London: Prentice-Hall, 1997.

GUJARATI, D. N. Econometria básica. São Paulo: Makron Books, 2000.

HAIR, J. F. et al. Análise multivariada de dados. 6. ed. Porto Alegre: Bookman, 2009.

INSTITUTO BRASILEIRO DE GEOGRAFIA E ESTATÍSTICA (IBGE). Aquisição Alimentar Domiciliar per capita Brasil e Grandes Regiões. Comunicação Social. Dez. 2010.

JURAS, A. A.; CINTRA, I. H. A.; LUDOVINO, R. M. R. A Pesca na área de influência da Usina Hidrelétrica de Tucuruí, estado do Pará. Bol. Téc. Cient. CEPNOR, Belém, v. 4, n. 1, p. 77-88, 2004.

MAGALHÃES, S. B. et al. Transformações Sociais e Territoriais no Ambiente Rural da Amazônia Oriental. Encontro Nacional da Anppas, 6. Anais... Belém: set. 2012.

MANESCHY, M. C.; ÁLVARES, M. L. M. Mulheres na pesca: trabalho e lutas por reconhecimento em diferentes contextos. Revista Coletiva, n. 1, jul./ago.set./2010. Disponível em: <http://www.coletiva.org/site/index. php?option $=$ com_k2\&view $=$ item\&layout $=i$ tem $\& i d=1$ 2\&Itemid $=76 \&$ idrev $=2>$. Acesso em: 18 set. 2013.

McGRATH, D. G. et al. Políticas e instituições: uma abordagem ecossistêmica de manejo da várzea do
Baixo Amazonas. Papers do NAEA, n. 243. Belém, out. 2009.

MERONA, B. Aspectos ecológicos da ictiofauna no baixo Tocantins. Acta Amazônica. Manaus: INPA, v. 16/17, n. único, 1986/87.

- et al. Os peixes e a pesca no baixo Rio Tocantins: vinte anos depois da UHE Tucuruí. 2010.

PASQUOTTO, V. F; MIGUEL, L. de A. Pesca Artesanal e Enfoque Sistêmico: uma atualização necessária. Anais... Encontro da Sociedade Brasileira de Sistemas de Produção, 6. SBSP, Aracaju, 2004.

SANTANA, A. C.; SANTOS, M. A. S. O mercado de caupi no estado do Pará: aplicação do método dos momentos generalizados. Revista Ciências Agrárias, n. 334, p. 47-58, jul./dez. 2000.

. Elementos de economia, agronegócio e desenvolvimento local. Belém: GTZ; TUD; UFRA, 2005.

.; CARVALHO, D. F.; MENDES, F. A. T. Análise sistêmica da fruticultura paraense: organização, mercado e competitividade empresarial. Belém: Banco da Amazônia, 2008.

SANTANA, A. C. et al. O mercado de frutas no estado do Pará: 1985 a 2005. Revista de Estudos Sociais, v. 13, n. 1, p. 174-185, 2011.

VASCONCELOS, M.; DIEGUES, A. C.; SALES, R. R. Alguns aspectos relevantes relacionados à pesca artesanal costeira nacional, 2007 Disponível em: < http://www. usp.br/nupaub/SEAPRelatorio.pdf $>$. Acesso em: 20 mai. 2012. 